\title{
DESMONTE DAS POLÍTICAS PÚBLICAS, RETRAÇÃO DOS DIREITOS TRABALHISTAS E A INTERVENÇÃO DO SERVIÇO SOCIAL DURANTE A PANDEMIA DA COVID-19: DESAFIOS E RESISTÊNCIAS!
}

\author{
DISMANTLING PUBLIC POLICIES, RETRACTION OF LABOR RIGHTS AND THE INTER- \\ VENTION OF SOCIAL WORK DURING THE COVID-19 PANDEMIC: CHALLENGES AND \\ RESISTANCE!
}

\begin{abstract}
Resumo
O presente trabalho tem como principal objetivo compreender como a retração dos direitos sociais e trabalhistas repercutem na intervenção das(os) profissionais do serviço social, das áreas da assistência social e saúde pública durante o período pandêmico. Além disso, intenta relatar as estratégias de resistência dessas profissionais para lidar com o desafio de atuar com gestões impositivas e com as novas e velhas imposições institucionais. Nesta perspectiva, este artigo, de caráter qualitativo, buscou analisar o conteúdo do vídeo intitulado: "Expressões sociais: política, direitos e intervenção do serviço social" associando-o à seleção de material bibliográfico e documental, sem recorte temporal. Sendo assim, concluiu-se que a constitucionalização dos ajustes fiscais e a terceirização do trabalho obstruem respostas contundentes da Política Pública de Assistência Social à população, bem como impulsionam o colapso no Sistema Único de Saúde (SUS), de uma maneira que aumentam e aprofundam as demandas sociais ao

1 Assistente social e mestranda do Programa de Pós-Graduação em Serviço Social da Universidade Federal da Bahia (PPGS-UFBA). E-mail: josivieira.as@gmail.com.

2 O vídeo faz parte da playlist intitulada: Plantão da quarentena\#47 e integra uma série, disponibilizada pelo canal Esquerda Online (EOL), que aborda temas variados que se vinculam ao novo coronavírus no Brasil.
\end{abstract}


longo do combate a Covid-19. ${ }^{3}$ Esse encadeamento rebate, diretamente, na vida pessoal e no processo de trabalho das(os) assistentes sociais de forma que exige intervenções mais atentas, capacitadas e que fortaleçam as iniciativas direcionadas à resistência a essa conjuntura.

Palavras-chave: Serviço social. Assistência social. Saúde. Covid-19.

\begin{abstract}
The main objective of this study is to verify how the retraction of social and labor rights has an impact on the intervention of social service professionals, in the areas of social assistance and public health during the pandemic period. With this, it attempts to report the resistance strategies used by these professionals to deal with the challenge of acting with imposing management and with new and old institutional impositions. Thus, this qualitative article analyzed the content of a video titled: "Social expressions: politics, rights and social service intervention", associating it to the selection of bibliographic and documentary material, with no timeframe. The constitutionalization of fiscal adjustments and the outsourcing of work were shown to obstruct strong responses of the Public Policy of Social Assistance to the population, as well as driving the collapse in the Unified Health System (SUS) in the same way that social demands increase and deepen during the fight against Covid-19. This association directly affects the personal life and work process of social workers. Demanding more attentive, trained interventions that strengthen initiatives aimed at resisting against this situation.
\end{abstract}

Keywords: Social work. Social assistance. Health. Covid-19.

\title{
INTRODUÇÃO
}

O serviço social é uma profissão que tem uma orientação firmada junto a ética profissional, em busca da consumação do projeto ético-político. Isso indica a árdua função de remar na contracorrente, mesmo que seja uma profissão com pouco prestígio social e uma categoria que não é bem remunerada. Para contestar os requerimentos institucionais é fundamental que $\mathrm{a}(\mathrm{o})$ profissional seja capacitada/o para propor, negociar e defender o campo de trabalho e as qualificações e funções profissionais. Sendo assim, deve ser uma trabalhadora ou um trabalhador assalariada(o) que vende sua força de trabalho para poder viver e "que não recusa as tarefas socialmente atribuídas [...] mas lhes atribui um tratamento teórico-metodológico e ético-político diferenciado". (IAMAMOTO, 2005, p. 80) Tais habilidades visam alcançar os fundamentos das demandas apresentadas, superando o imediatismo das respostas prontas, tendo em vista o particular sem estar desconectado do todo.

3 De acordo com a Fundação Oswaldo Cruz: “[...] COVID significa COrona VIrus Disease (Doença do Coronavírus), enquanto '19' se refere a 2019 [...]”. 
Demandas novas e que precisam de respostas eficazes caracterizam esse período pandêmico que tem desafiado profissionais de todas as áreas. As mais de 126.650 pessoas mortas no Brasil, por causa da Covid-19, têm causado muitas justificativas que responsabilizam a pandemia pela ineficiência das políticas públicas e pelo alto índice de desempregados. (ORGANIZAÇÃO MUNDIAL DA SAÚDE, 2020; TAVARES, 2020) Mas até que ponto essa justificativa é plausível? Será mesmo que foi a pandemia que ocasionou o colapso nas políticas públicas? É ela responsável pelo crescente número de desempregos? Como esses fatos têm interferido no trabalho dos assistentes sociais? Quais as formas de enfrentamento desenvolvidas por eles?

Pois bem, é importante assinalar que, neste estudo, o objetivo principal é analisar como a retração dos direitos sociais e trabalhistas têm impactado na atuação da(os) assistentes sociais que estão vinculadas(os) ${ }^{4}$ às Políticas Públicas de Saúde e Assistência Social durante a pandemia.

Assim como pretende-se propagar as estratégias de luta e resistências dos profissionais, que mesmo diante do desmantelamento da Seguridade Social $^{5}$ e do esvaziamento dos diretos trabalhistas, lembrando que "antes de ser um profissional, [...] é um trabalhador, está inserido num determinado contexto [...] são pessoas [..] não são protegidos [...] e são assediados de uma maneira inadmissível" (MOTA, 2020, informação verbal), desvelam um posicionamento atitudinal vinculado à população, coerente com a ética profissional, segurança pessoal, vida dos usuários e qualidade dos serviços prestados.

Empenhando-se para alcançar esses objetivos, foi realizada uma análise do conteúdo da live (em homenagem ao dia dos assistentes sociais, comemorado dia 15 de maio de 2020) que foi realizada e pode ser assistida pelo portal Esquerda Online (EOL). A entrevista realizada teve como mediadora Carol Burgos, jornalista da Esquerda Online, e contou com a presença das assistentes sociais: Ivanete Boschetti, ${ }^{6}$ Ana Elizabete Mota, ${ }^{7}$ Karina Vidal ${ }^{8}$ e Marcella Azevedo. ${ }^{9}$ Essas assistentes sociais apresentaram aspectos relevantes sobre o contexto que

4 Desse momento em diante, todas as vezes em que mencionarmos "os profissionais, os trabalhadores, os assistentes sociais" ou termos similares leia-se: as(os) profissionais, as(os) trabalhadoras(es), as(os) assistentes sociais, de forma a abranger os dois gêneros.

5 Art. 194. A seguridade social compreende um conjunto integrado de ações de iniciativa dos Poderes Públicos e da sociedade, destinadas a assegurar os direitos relativos à saúde, à previdência e à assistência social.

6 Professora titular da Escola de Serviço Social da Universidade Federal do Rio de Janeiro (UFRJ).

7 Professora aposentada da Universidade Federal de Pernambuco (UFPE) e professora visitante da Escola de Serviço Social da UFRJ.

8 Assistente social que atuou na Secretaria de Assistência social de São José do Rio Preto e é doutoranda em serviço social pela Pontifícia Universidade Católica de São Paulo (PUC-SP).

9 Assistente social da área da saúde e da Emergência Regional da Barra da Tijuca/RJ. 
antecedeu a pandemia no Brasil e sobre os impactos dessa conjuntura na atuação de assistentes sociais da área da saúde e da assistência social.

Para a construção deste artigo, primeiramente, houve a transcrição de toda a live e, após, um levantamento bibliográfico e documental. Em seguida, uma análise sobre quais falas estavam vinculadas ao que se propõe este artigo. No intento de alcançar os objetivos deste estudo qualitativo, as falas das convidadas foram recortadas e intercaladas com a pesquisa realizada em livros, artigos, sítios eletrônicos e documentos. Precisa-se ressaltar que envidou-se esforços para manter o que foi proferido, na live, em contexto original e fiel.

Ainda buscando alcançar os propósitos principais deste artigo, realizou-se três divisões além desta introdução, do resumo e das referências. A primeira parte se dispõe a fazer um panorama sobre a Seguridade Social e sobre a terceirização do trabalho. Na segunda e terceira parte iremos observar, por meio dos fragmentos do relato de Karina Vidal e Marcella Azevedo, como o desmonte das políticas públicas e a flexibilização dos direitos trabalhistas impactam na atuação profissional e quais estratégias de resistência têm sido desenvolvidas coletivamente.

Karina Vidal, segunda convidada a se apresentar, falou como a Política Pública de Assistência Social está sendo ofertada no município de São José do Rio Preto e sobre a organização dos trabalhadores pela garantia do direito à vida dos trabalhadores e da população e por condições adequadas de trabalho. $O$ último relato será o de Marcella Azevedo, ela descreveu um cenário de: desmonte da Política Púbica de Saúde e redução dos postos de trabalho. Expôs, também, algumas demandas institucionais que estão sendo atribuídas aos assistentes sociais e propôs algumas possibilidades diante das novas e velhas imposições institucionais.

\section{NÃO FOI A PANDEMIA}

Durante o vídeo, as convidadas se esforçaram para dar visibilidade ao o fato de que a pandemia não foi a geradora da crise, mas que ela catalisa e revela um quadro que envolve questões como: desmonte das políticas públicas e a retirada dos direitos trabalhistas.

Boschetti (2020) abriu o encontro abordando que algumas medidas implementadas antes da pandemia e se unirem a outras na pós-pandemia, significando a "desapropriação do mínimo de garantia dos direitos da classe trabalhadora». Ela citou alguns desses "ajustes fiscais permanentes": terceirização, contrarreformas da Previdência Social, reforma trabalhista e a EC n ${ }^{\circ} 95$. 
Iamamoto (2005) mostra que o deterioramento da prestação de serviços sociais públicos e a compreensão das verbas orçamentárias (no atual momento, reduzida e subordinada) deixam claro o quanto o Estado reduz suas responsabilidades e ações sociais. De acordo com Sara Granemann (2016), a Emenda Constitucional $\mathrm{n}^{\circ} 95$, que institui o Novo Ajuste Fiscal, transforma os gastos mínimos com a Seguridade Social, visto que essa encontra-se em uma suposta e eterna crise, e com a Política Pública de Educação em máximo e redimensiona o fundo público. A mencionada autora, completa:

Somente os "gastos" estatais destinados à efetivação de direitos das trabalhadoras e trabalhadores devem ser submetidos ao austero programa. A razão para tão vulgar ataque reside na necessidade dos grandes capitais em operar uma nova partilha do fundo público que lhes permita, simultaneamente, o enfrentamento da crise e a abertura de novos espaços de inversão de seus capitais.

Redimensiona-o como? Desconstitucionaliza, congela, reduz, desconstrói e limita aos gastos federais com as políticas sociais por vinte anos, ${ }^{10} 20$ anos! Desvincula a Seguridade Social e a educação das fontes de receitas próprias e vinculadas aos seus orçamentos, conforme previstas na Constituição Federal de 1988. Subordina e associa essas fontes ao aumento da inflação acumulada no ano anterior, conforme o Índice Nacional de Preços ao Consumidor Amplo (IPCA).

É importante sublinhar que os direitos sociais são as expressões dos "sujeitos falantes" que lutaram para que suas reivindicações por justiça e igualdade fossem inscritas no maior marco legal do país. A vinculação dessa conquista a custos ou a ônus é sufocar vozes que, através do dissenso, fixaram sua presença no cenário público, político e jurídico. Retrair direitos é destruir as barreiras que, dentro de certos limites, obstam a assimetria nas relações sociais e "fornecem proteções contra as incertezas da economia e os azares da vida". (TELLES, 1998, p. 37)

Ainda sobre medidas que agravam o cenário pandêmico, foi citada a terceirização do trabalho. Essa não é apenas uma forma de precarizar o trabalho, também desestabiliza toda a vida social da classe trabalhadora, gira em torno da volatilidade, efemeridade, e descartabilidade "estamos defronte de novas modalidades e modos de ser da precarização, da qual a terceirização tem sido

10 Com o título: Promulgada Emenda Constitucional do Teto de Gastos Públicos, o site do Senado Federal, noticia que EC 95 foi aprovada e explica como essa legislação disciplina os gastos federais. 
um de seus elementos mais decisivos". (GRAÇA; ANTUNES, 2015, p. 25) Verifica-se, desse modo, a intensificação de mulheres e homens que se tornaram trabalhadores descartáveis, desprotegidos e submetidos a flexibilização da legislação trabalhista, resultando na contínua e acentuada destituição dos direitos que foram arduamente conquistados.

Druck (2011) diz que a terceirização é uma das faces da precarização do trabalho e que firma-se na desculpa da necessidade de sobrevivência das empresas. Hoje, justifica-se de acordo com a "lógica da acumulação financeira que, [...], exige total flexibilidade em todos os níveis, instituindo um novo tipo de precarização que passa a dirigir a relação entre capital e trabalho em todas as suas dimensões [...]". (DRUCK, 2011, p. 49)

A notícia intitulada: "Desemprego aumentou antes da chegada do coronavírus no Brasil, mostra IBGE”, veiculada pelo site Carta Capital, no dia 31 de março de 2020, relata que setores que "tradicionalmente" não demitiam ao final do ano foram os responsáveis pelo aumento no número de desempregados no país. Mas isso não quer dizer que quem têm o histórico de registrar alto índice de demissão rompeu com seu legado, mas, sim, que outros setores foram adicionados a esse "cenário negativo".

O resultado do combo (desmonte das políticas públicas e retração dos direitos trabalhistas) é o alto índice de desemprego anterior a pandemia, impulsionando a procura pelos equipamentos públicos na tentativa de obter o mínimo do mínimo para a sobrevivência "[...] as solicitações que chegam até os equipamentos, por parte da população, é com relação ao auxílio do governo, dos $\mathrm{R} \$ 600,00$, e com relação a cesta básica". (VIDAL, 2020, informação verbal)

Filas quilométricas de pessoas "invisíveis" (PINHEIRO, 2020), em busca do auxílio do governo federal, se formaram por todo o país. Muitos desses não receberam o auxílio, visto que não foram considerados dentro do padrão socioeconômico e, vários outros, sequer o perfil passou do processo de análise. Quanto aos "homens empregáveis no curto prazo" podem não receber o auxílio, por estarem acima da renda dos elegíveis para o programa, ou seja, estão completamente descobertos: sem o direito ao auxílio emergencial e sem o direito ao seguro-desemprego.

O aumento da pauperização e, por sua vez, da procura por serviços públicos se esbarram nos cortes com os gastos sociais ampliando "a seletividade dos atendimentos, fazendo com que a proclamada universalização aos direitos sociais se torne letra morta" e o assistente social "um juiz rigoroso da pobreza". (IAMAMOTO, 2005, p. 160) "[...] A insuficiência de medidas para suprir aquilo que restou do desmonte mercantil e financeirizado do fundo público e das po- 
líticas, por eles financiadas, afetam diretamente a profissão de serviço social [...]". (MOTA, 2020, informação verbal)

Conforme mencionado, os assistentes sociais são trabalhadores e, portanto, sofrem as mesmas consequências, pressões, negligências e vexames que a "classe-que-vive-do-trabalho", como: precarização das políticas públicas e o esvaziamento dos direitos trabalhistas. A conjuntura nos impõe limites dos mais diversos, como alguns pontuados aqui, mas também abre possibilidades "[..] sempre existe um campo para ação dos sujeitos [...]". (IAMAMOTO, 2005, p. 21) Na sequência, veremos o relato de duas assistentes sociais que contam: como têm sido atuar nas políticas públicas com orçamento reduzido, como a terceirização e o desemprego tem atingido a rotina de trabalho, como elas lidam com gestões impositivas e com as demandas institucionais que são impostas como atribuições profissionais. Isso, no contexto pandemia da Covid-19.

\section{“[...] DISPONIBILIZAR OS CORPOS DOS PROFISSIONAIS [...]"}

Karina Vidal atuou na Secretaria de Assistência Social (SEMAS) de São José do Rio Preto (SJRP), é doutoranda da Pontifícia Universidade Católica de São Paulo (PUC - SP) e falou logo após Ivanete Boschetti. Ela descreveu sua realidade de trabalho e contou sobre a luta para garantir melhorias na execução da política do Sistema Único de Assistência Social (SUAS) e por condições para trabalhar de forma segura e sem constrangimentos.

Ao narrar sobre como a gestão municipal lidou com a segurança dos trabalhadores e da população atendida, mesmo diante do elevado risco de contágio e da necessidade de organização para lidar com a pandemia, Karina contou que houve omissão da SEMAS e que a única medida realizada pela chefia "foi, exclusivamente, colocar os trabalhadores na linha de frente, não foi feita nenhuma medida pra além disso". (VIDAL, 2020, informação verbal)

As ações conduzidas pelo órgão gestor não tem considerado nenhum dos aspectos determinados pela regulamentação deste benefício, a ação exclusiva de disponibilizar os corpos dos profissionais nesta situação remete a uma ausência de compreensão que incorpora o escopo da política e uma irresponsabilidade, ausência de garantias mínimas e cuidado com os(as) trabalhadores(as) que neste contexto também encontram-se em uma situação de ameaça a vida. Carta Aberta, FTM-SUAS (2020).

11 Trecho retirado da carta aberta escrita pelo FTM-SUAS (2020). 
Karina disse, ainda, que quando compareceu ao Centro de Referência Especial de Assistência Social (CREAS), a chefia de Proteção Social Especial informou que eles receberiam "orientações com relação ao funcionamento dos serviços executados pela política". No entanto, relatou ela, ao questionarem sobre um plano de ação ou de contingência, foi informado que "não havia nenhum direcionamento".

De imediato, segundo Karina, o realizado foi: "revezamento entre trabalhadores [...], suspensão das atividades dos grupos [...] e a orientação de que visitas e atendimentos presenciais deveriam ocorrer em caso de extrema necessidade". Diante do exposto, Karina explicou que houve uma organização dos trabalhadores, por meio do Fórum Municipal dos Trabalhadores do Sistema Único de Assistência Social (FTM-SUAS) de SJRP, e foi dada origem a uma carta aberta, a qual foi protocolada no dia 27 de março de 2020, na SEMAS, e encaminhada aos demais órgãos competentes.

Vale mencionar que o subtítulo: "[...] disponibilizar os corpos dos profissionais [...]" foi um trecho extraído da carta aberta emitida pelo FMT-SUAS (2020). A carta escrita pelos trabalhadores encontra-se no site do Conselho Regional de Serviço Social de São Paulo (CRESS-SP) e aponta: denúncias, algumas sugestões para regularização das condições de trabalho e a necessidade de uma regulamentação dos benefícios eventuais no município, observemos algumas: ${ }^{12}$

- Ausência de Equipamentos de Proteção Individual (EPI's);

- Ausência de orientações adequadas de como atender e lidar com as questões referentes a pandemia;

Ausência de protocolos de atendimento;

Condução desordenada e desarticulada por parte da Assistência Social do Município;

Necessidade de que os trabalhadores do SUAS componham o Comitê Gestor de Enfretamento ao novo Coronavírus;

- Necessidade de diálogo aberto com os trabalhadores;

Necessidade de intensificar o quadro de funcionários;

- Falta de proposta de proteção para população em situação de rua;

- Falta de vacinação contra gripe para trabalhadores;

Urgência de regulamentação específica dos Benefícios Eventuais;

12 Por questão de otimização, foram feitos alguns recortes e adaptações na escrita de alguns elementos notificados. Para maior aproximação com o relato dos profissionais, indica-se leitura do próprio documento. 
Quantidade limitada e reduzida de benefícios, os quais não atendem as questões apresentadas no momento de pandemia;

- Servidores obrigados a deslocar-se pelo município, ainda que contaminados, para a coleta de exames da Covid-19, visto que só serão acatados os atestados provenientes da Unidade Básica de Saúde da Família Lealdade e Amizade. Decreto $\mathrm{n}^{0} 18.564$ de 24 de março de 2020;

- Atendimento de porta aberta que implica em risco eminente tanto aos trabalhadores quanto à população. Decreto $\mathrm{n}^{\circ} 18.554$ de 16 de março de $2020 ; ;^{13}$

Terceirizados trabalhando desprotegidos;

- Estagiários convocados para atuar de forma desprotegida e sem vínculo formal.

De acordo com o que foi acima citado, observa-se um sistema de desproteção dos trabalhadores. Sem proteção trabalhista para alguns e sem proteção à vida para a maioria. Ao abordar o terceiro tipo de precarização social, Druck (2011) fala sobre a insegurança e a saúde do trabalhador e de como são atingidos por não receberem o treinamento correto ou por não conhecerem os riscos e as formas de prevenção de doenças a que estão expostos. Dessa forma, o número de acidentes, mortes e doenças do trabalho aumentam por causa do desrespeito dos empregadores às normas de segurança.

Ainda de acordo com a autora, quanto mais precário é o vínculo trabalhista mais exposto o trabalhador está à insegurança e às doenças. Os terceirizados, apesar de serem os que mais trabalham, são os que recebem os menores salários, os que têm menos direitos trabalhistas e são, também, os mais expostos aos riscos à saúde provindos do exercício profissional e a morte, tais situações se originam "exatamente desta condição mais precária de trabalho". (DRUCK; ANTUNES, 2015, p. 27)

É importante assinalar que uma das formas prevenção ao novo coronavírus é manter o distanciamento físico (TANIGUCHI, 2020), então se esses trabalhadores não recebem: treinamento adequado, não têm um protocolo específico para o atendimento dos usuários, não recebem os EPI's, circulam pela cidade (com a possibilidade de estarem contaminados), colocam em risco não só a saúde deles, terceirizados ou não, mas, também, a saúde e vida da população?

13 A partir desse marcador, os trabalhadores, possivelmente, posicionam-se com relação ao disposto no Decreto $\mathrm{n}^{\circ} 18.554$ de março de 2020. 
Com os apontamentos acima, feitos pelos trabalhadores do SUAS, observa-se, também, que a Política de Assistencial Social de SJRP não tinha uma regulamentação específica dos benefícios eventuais. Se for assim, vale lembrar que esse tipo de benefício é compreendido pela Lei $\mathrm{n}^{\circ}$ 8.742, de 07 de dezembro de 1993, como "as provisões suplementares e provisórias que integram organicamente as garantias do Suas e são prestadas aos cidadãos e às famílias em virtude de nascimento, morte, situações de vulnerabilidade temporária e de calamidade pública". Sendo assim, será que o município já poderia estar preparado ou organizado para possíveis eventualidades e, dessa forma, responder às necessidades da população durante a pandemia?

Karina cita que houve outra carta enviada a SEMAS-SJRP, no dia 06 de abril de 2020. No entanto, no site do CRESS-SP, até o momento da finalização deste artigo, encontra-se apenas a citada nesse trabalho. Por esse motivo, não referenciamos esse outro documento elaborado pelo FTM-SUAS. De acordo com a segunda palestrante, essa carta é fundamentada "em pesquisa e contatos realizados em outros municípios, são feitas diferentes propostas no que tange ao atendimento da política municipal, resguardando a saúde dos trabalhadores bem como da população atendida [...]". (VIDAL, 2020, informação verbal)

No dia 14 de abril de 2020, o CRESS-SP apresenta, em seu site, a notícia intitulada: Trabalhadoras(es) do SUAS de São José do Rio Preto atuam com dificuldades durante a pandemia. ${ }^{14} \mathrm{~A}$ notícia informa que o CRESS, após receber as denúncias feitas pela carta aberta, realizou uma reunião com a SEMAS dia 8 de abril de 2020.

De acordo com o relato completo da reunião, foi emitida uma notificação solicitando que a SEMAS se posicionasse sobre quais providências havia tomado e as que estavam visando realizar para a "proteção da vida e saúde das trabalhadoras e trabalhadores, e usuárias e usuários do Sistema Único de Assistência Social (SUAS) [...]".

Sendo assim, o relato diz que a SEMAS informou, em reunião, que: "a secretaria [...] envidou esforços na construção de portarias, contratação de serviços, compra de insumos e, estudos sobre questões importantes e pertinentes ao período de calamidade [...]", comprou material de proteção, que "começou a chegar nessa semana, e está sendo distribuído para todos os serviços".

A respeito de como os serviços seriam ofertados a população, visando a segurança e proteção dos participantes, o relato informa que a SEMAS declarou

14 No site do CRESS-SP, a notícia é abordada com o tema: Trabalhadoras(es) do SUAS de São José do Rio Preto atuam com dificuldades durante a pandemia da Covid-19 - Faltam EPIs e orientação para o atendimento seguro e de qualidade à população, disponibilizada no dia 14 de abril de 2020 . 
ter realizado "emissão de portaria municipal orientando as providências que devem ser adotadas para o funcionamento dos serviços de assistência social com a devida proteção à saúde de todas(os) envolvidas(os) [...]".

Nessa ocasião, foi feito o seguinte questionamento a SEMAS: "qual a possibilidade e capacidade do município reivindicar junto ao governo federal a revogação imediata da Emenda Constitucional $n^{\circ} 95$ e outras normas que agudizam o cenário de precarização e desmantelamento das políticas públicas, em especial a de assistência social".

A Secretaria de Assistência Social do município de São José do Rio Preto - SP, afirmou, na mencionada reunião com o CRESS-SP, ter realizado medidas de prevenção e cuidado com a população e trabalhadores do SUAS, diante do estado de calamidade proveniente da Covid-19. No entanto, por questão de sintetização, alguns recortes na transcrição das falas foram realizados. Sendo assim, sugere-se a leitura do relato completo no site do CRESS-SP.

As providências adotadas, com relação ao funcionamento dos serviços, mencionada pela SEMAS, pode ser a Portaria $n^{\circ}$ 03/2020 de 23 de março de 2020, ${ }^{15}$ que regulamenta "as determinações de organização dos atendimentos e serviços, frente as medidas de prevenção e enfrentamento a pandemia do coronavírus (Covid-19)" e resolve estabelecer o rodízio ou teletrabalho para os servidores da assistência social do município.

Artigo $2^{\circ}$ - Adotar, em todas as unidades de atendimento e departamentos da Secretaria Municipal de Assistência Social, quando tiver número de servidores suficientes para as atividades essenciais de Proteção Social, o regime de rodízio ou de teletrabalho, a fim de reduzir a permanência e circulação de pessoas em cada local, intercalando a jornada dos trabalhadores de modo a manter os atendimentos e funções essenciais nos locais de trabalho [...]. Portaria $\mathrm{n}^{\circ}$ 03/2020.

Pois bem, Karina relatou que, depois que os servidores se organizaram e reagiram a falta de planejamento e estruturação na execução da Política de Assistência Social Municipal, no intento de atender devidamente à população e aos trabalhadores diante da realidade pandêmica, eles sofreram: "[...] diversas manifestações assediadoras, por parte das chefias [...] que publica uma nova portaria [...] que coloca fim no rodízio [...]."

15 A Portaria ${ }^{\circ}$ 03/2020 rege sobre as "novas determinações de organização dos atendimentos e serviços da Secretaria Municipal de Assistência Social frente as medidas de prevenção e enfrentamento a pandemia do coronavírus (Covid-19)". 
A legislação, citada por Karina, foi publicada no diário oficial do município no dia 12 de abril de $2020,{ }^{16}$ mas é originada no dia 09 de abril de 2020 e versa sobre as medidas para a execução do regime de rodízio:

Artigo $1^{\circ}$ - Fica suspenso, em todas as unidades de atendimento e departamentos da Secretaria Municipal de Assistência Social o regime de RODIZÍO (grifo do autor) ${ }^{17}$ regulamentado no artigo $2^{\circ}$ da Portaria SEMAS 03/20. Portaria ${ }^{0}$ 06/2020.

Vale lembrar que a Portaria $\mathrm{n}^{\circ}$ 03/2020, publicada no diário oficial do município no dia 24 de março de 2020 , disciplina as determinações sobre a organização dos serviços e atendimentos da Secretaria de Assistência Social, ou seja, define como, daquele momento em diante, já no período de pandemia, e quais medidas seriam adotadas para a preservação e oferta dos serviços públicos e atividades essenciais. Visando "reduzir a permanência e a circulação de pessoas em cada local [...]" a mencionada legislação, institui, assim, o rodízio na escala de trabalho dos servidores.

Porém, na Portaria no 06/2020 (que é de um dia após a reunião com o CRESS-SP) a SEMAS impõe o fim do rodízio aos servidores. Isso quer dizer que, apesar de ter acordado, na reunião com conselho, que garantiria "alguns aspectos que estavam sendo reivindicados nesses documentos" (VIDAL, 2020, informação verbal) a gestão suspende o rodízio de trabalho. Dessa forma, "fluxo de atendimento volta a ser normalizado, com visitas domiciliares nos territórios e o atendimento é presencial, normal [...]", de acordo com a segunda palestrante. (VIDAL, 2020, informação verbal)

Conforme apresentado, a generalidade das demandas expostas nas cartas são oriundas do período que precede a pandemia e exprimem a necessidade de uma organização na oferta dos serviços do SUAS, serviços de extrema importância para a população, ainda mais em tempos da pandemia da Covid-19, visto que essa política visa a garantia dos "mínimos sociais e provimento de condições para atender contingências sociais e promovendo a universalização dos direitos sociais". (BRASIL, 1993) As cartas não são orientadas ao favorecimento dos servidores, mas ao conjunto societário que deveria ter acesso ao que é inerente a Política Pública de Assistência Social. Karina (2020) pontua: "[...] é mais

16 Colocar na busca a data 12 abr. 2020 e a palavra-chave "portaria nº6". PREFEITURA DE RIO PRETO, [2020]. Encontre o que você procura no portal. Disponível em: https://www.riopreto.sp.gov.br/ DiarioOficial/Diario.action. Acesso em: 22 jun. 2020.

17 O grifo e o tamanho da fonte encontram-se na Portaria $n^{\circ} 06 / 2020$. 
que urgente que o movimento de luta seja fortalecido de forma coletiva e que todas as manifestações autoritárias e arbitrárias sejam repudiadas". (KARINA, 2020, informação verbal)

\section{“NÃO SOMOS HERÓIS"18}

Marcella Azevedo, assistente social da área da saúde, servidora da Emergência Regional da Barra da Tijuca, Rio de Janeiro (RJ), falou antes da convidada Ana Elizabete Mota, quarta e última convidada a se apresentar. Marcella contou um pouco sobre sua vivência como profissional que atua diretamente na linha frente dos serviços públicos e atividades essenciais. Inserida no contexto em que a Política Pública de Saúde do Rio de Janeiro reverbera a submissão dos serviços de atenção primária à política de cortes e otimização dos recursos, ela abordou o tema "Determinantes sociais e econômicos". Falou, também, como demandas que são institucionais estão sendo atribuídas aos assistentes sociais e destacou como os profissionais de serviço social podem munir-se contra tais imposições.

Ao falar ${ }^{19}$ sobre o desmonte da política de saúde no contexto de precarização dos serviços e do atendimento, Marcella explanou: "[...] a terceirização e precarização desses serviços, a inclusão da nova Política de Atenção Básica que prevê a redução das equipes. Milhares de agentes comunitários de saúde demitidos [...]". Sob justificativa de corte orçamentário, as demissões e extinções das equipes da saúde da família estão sendo feitas em larga escala no Rio de Janeiro. (TCHAO, 2019) Uma amostra da quantidade de profissionais de saúde que estão sendo demitidos pode ser feita com base nos números noticiados pelo Sindicato dos Auxiliares e Técnicos em Enfermagem do Rio de Janeiro (SATEMRJ).

De acordo com o SATEMRJ, o número de demissões dos profissionais de saúde que trabalhavam na Organização Social Viva Rio chegou a "5.336 trabalhadores das 76 clínicas da família e centros municipais de saúde gerenciados pela OS, incluindo técnicos de enfermagem, farmacêuticos, fonoaudiólogos e outros".

As demissões, as privatizações, os atrasos dos salários, a redução das equipes da saúde básica (PREFEITO..., 2020) não ocorrem pacificamente, ${ }^{20}$ sem processo de enfrentamento e recusa da classe trabalhadora "[...] resistir a todos

18 Frase mencionada por Marcella no decorrer de sua fala.

19 A fala da terceira convidada foi recortada para que houvesse a intercalação com as ideias da autora e com a pesquisa realizada. No entanto, envidou-se esforços para mantê-la em contexto original.

20 Em 11 de dezembro de 2019, o G1 informa: Crise na Saúde do Rio: entenda o que levou à greve e à restrição no atendimento - Funcionários reclamam que estão há dois meses sem salários. Rede municipal sofre com falta de pessoal e de insumos. Pacientes sofrem na peregrinação por atendimento. 
esses desmontes [...], questionar, não achar que isso tudo pode ser normal [...] vidas acima de lucros! Esse tem que ser o nosso lema". (MARCELLA, 2020, informação verbal) Para Telles (1998), a demolição dos serviços públicos e sua consequente privatização, sob o discurso de que é uma modernização necessária para mercado ou de que os serviços públicos são dispendiosos, é uma "operação insidiosa que elide a questão da responsabilidade pública”. (TELLES, 1998, p.35) Significam um atraso para os "sempre precários serviços públicos" e desvinculam a noção de direito da justiça e da igualdade, dessa forma, aumentado a disparidade social.

A página Rede Brasil Atual, no dia 1 de maio de 2020, mostra como as privatizações e a terceirização precarizam os serviços públicos e o trabalho ao veicular a seguinte notícia: "Afastados e terceirizados, técnicos de enfermagem sofrem com perda salarial no Rio de Janeiro - Redução de direitos é reflexo da política de cortes implementada pela prefeitura e do abandono por parte de algumas organizações sociais que administravam unidades de saúde".

Pode-se constatar, nessa reportagem, que apesar de exercerem as mesmas funções que outros servidores, os terceirizados são mais atingidos pela combinação da demolição das políticas públicas e retração dos direitos trabalhista. Devido a política de corte nos gastos públicos e a quebra de contrato com algumas organizações sociais, os terceirizados foram demitidos em massa. De acordo com Druck (2011): "É o tempo de novos (des) empregados, de homens empregáveis no curto prazo, através das (novas) e precárias formas de contrato [...]". (DRUCK, 2011, p. 43)

O reflexo desse "reordenamento" vivenciado pela população é o crescimento da crise na saúde em meio a pandemia ${ }^{21}$ "[...] o que importa agora é o jaleco do SUS, o jaleco do SUS não apaga o desmonte a que foi submetida a política de saúde brasileira!". (MOTA, 2020, informação verbal) Só que, agora, esse sucateamento, que é anterior a pandemia, está sendo televisionado a todas as classes após a Covid-19.

Enquanto são aplaudidos e homenageados nas janelas, ${ }^{22}$ os profissionais trabalham com medo, insegurança e descaso "[...] não somos heróis, somos trabalhadores e precisamos de direitos, de respeito e condições de trabalho [...]". Em meio ás demissões, ao desmonte do SUS e sob a acentuada crise no sistema de saúde do Rio de Janeiro, amplia-se "[...] a necessidade de suporte

21 No dia 31 de março de 2020 , a página Tab Uol relata que o: Desmonte de Clínicas da Família deixa favelas vulneráveis à Covid-19 no Rio.

22 O Conselho Federal de Enfermagem (COFEM) apresenta, no dia 21 de março de 2020, em seu site oficial, a informação: Brasileiros aplaudem profissionais de saúde pelo combate ao coronavírus - Movimento espontâneo foi organizado pelas redes sociais. 
à saúde dos trabalhadores, que estão na linha frente, muitos machucados, não só fisicamente (uso de máscaras) como também emocionalmente [...]". (MARCELLA, 2020, informação verbal)

No decorrer de sua fala, ela mencionou alguns pontos (demandas agravadas durante a pandemia, de condições de trabalho, não restringindo-se a unidade em que atua) que sinalizam o que é ser da linha de frente na área da saúde:

- Aumento exponencial das demandas nas unidades de saúde;

Aumento exponencial em relação a violência intra doméstica;

- Aumento de demandas para orientações sobre o auxílio da assistência e auxílio emergencial do governo;

Retomada da fome;

- Contexto do Rio de Janeiro (precarização, privatização e terceirização dos serviços);

Redução das equipes;

Demissão de milhares de agentes comunitários de saúde;

Medo e insegurança diante do contexto;

Escassez de EPI's ou inadequados;

Falta de treinamento para o uso correto dos EPI's;

Realização de triagem, no primeiro atendimento, realizada por assistentes sociais;

- Comunicação da evolução clínica feita por assistentes sociais;

- Comunicado do óbito feito por assistentes sociais.

Diante desse cenário, é possível observar vezeiras (e atuais) imposições institucionais que não têm aparato legal, desrespeitam o usuário, a família e o disciplinamento jurídico e político da profissão. Os marcos regulatórios da profissão dispõem e respaldam exatamente o contrário, tais demandas saem do âmbito da saúde e das denúncias feitas aos conselhos e ressurgem abertamente. $^{23}$

A título de exemplo, temos a comunicação do óbito. Sobre esse assunto, Marcella frisou: "[...] outra questão importante para pensar [...] é a chamada institucional, feita a categoria, para assumir novas demandas profissionais sob a justificativa da situação da calamidade pública [...]". Informar a morte do usuário dos serviços de saúde, não constitui atribuição ou competência profissional do assistente social!

23 O site do CRESS-AL, no dia 13 de maio de 2020, divulga uma "nota pública em resposta à matéria veiculada em telejornal de Alagoas sobre óbitos de vítimas do Covid-19". 
Deixar isso claro, impor esse limite, significa respeitar a família, que merece ter esclarecimentos qualificados por meio de respostas dadas por profissionais com conhecimentos específicos quanto a evolução do quadro e a causa da morte de seu parente. Isso faz parte de uma luta antiga da categoria. Os Parâmetros para a Atuação de Assistentes Sociais na Saúde (2009, p. 25), ao abordar sobre as ações em que a equipe não sabe corretamente quais são as competências dos assistentes sociais, dentro do quadro de profissionais, descreve que os empregadores têm: "[...] requisitado diversas ações aos profissionais que não são atribuições dos mesmos, a saber: convocação do responsável para informar sobre alta e óbito; comunicação de óbitos [...]".

Esse assunto, sempre é retomado, já que nunca deixou de existir nos corredores hospitalares. E diante da rapidez no aumento do número de mortos, aliada ao alto nível de tensão, conjuntura de pânico e urgência instalada, em pleno estágio do desmonte do SUS (CUNHA, 2020), recupera-se:

"[...] a gente já ouviu algumas denúncias de profissionais, que têm feito o processo seletivo para hospitais de campanha e têm sofrido assédio moral, cobrando a necessidade desse profissional, no momento da atuação, de estar junto com o médico na hora da comunicação do óbito [...]". (MARCELLA, 2020, informação verbal)

Sendo assim, no dia 31 de março de 2020, o Conselho Federal de Serviço Social (CFESS) divulga a Orientação Normativa $\mathrm{n}^{\circ}$ 03, que orienta o conjunto da categoria e a sociedade: "A comunicação de óbito não se constitui atribuição ou competência profissional do/a assistente social." Marcella frisou a importância de que a "categoria tenha clareza das demandas que reconhece, nesse momento, e não reconhece como sua atribuição". Mas o que devo fazer se me impuserem o contrário?

7. As determinações institucionais que estejam em desacordo com a legislação profissional (lei de regulamentação, código de ética e resoluções) devem ser informadas aos Conselhos Regionais de Serviço Social (CRESS) em suas jurisdições. (CFESS, 2020, p. 2)

Outro exemplo de demanda, que não é da profissão e que está sendo imposta como tal, de acordo com Marcella, é a:

"[...]comunicação da evolução clínica, em especial, aqui no Rio de Janeiro, né? O decreto do dia 15, ele suspende o processo das visitas 
e o direito a acompanhante. $E$ isso é muito grave e sério, porque o decreto ele, simplesmente, suspende, mas não indica como vai ser esse cuidado de direito a humanização desse atendimento. Então, a gente tem relatos de muitas famílias de usuários que não estão conseguindo mais manter contato com suas famílias de forma alguma". (MARCELLA, 2020, informação verbal)

A legislação citada pode ser a Resolução da Secretaria Municipal de Saúde (SMS), n 4.369 de 15 de abril de 2020, publicada do Diário Oficial do Munícipio, dia 17 de abril de 2020, que resolve: "a suspensão das visitas aos pacientes internados na Rede da SMS". Mas quem é que vai comunicar à família sobre a evolução clínica do usuário?

5. Ao(À) assistente social não cabe informar ao(à) paciente e/ou seus familiares sobre as condições clínicas de saúde, tratamentos propostos, evolução da doença e prognósticos, direitos estes que devem ser garantidos e assumidos por profissionais que tenham competência para tal.

6. Da mesma forma, não cabe ao(à) assistente social a divulgação de boletins médicos, nem tampouco o atendimento prévio de pacientes, visando realizar a triagem das suas condições clínicas para acesso aos serviços de saúde. (CFESS, 2020, p. 2)

Sendo assim, Marcella chamou a atenção para que estejamos aproximados com as legislações da categoria, para que o agir seja balizado na ética e que tenha como fim o projeto de intervenção profissional. Além disso, exortou sobre a necessidade de buscarmos informações em fontes seguras, científicas, como a Fundação Instituto Oswaldo Cruz (FIOCRUZ) "ir além das rotinas institucionais e buscar apreender o movimento da realidade para detectar tendências e possibilidades nela presentes passíveis de serem impulsionadas pelo profissional". (IAMAMOTO, 2005, p. 21)

Marcella falou, ainda, sobre a importância da luta coletiva a favor do SUS e deixou o convite para que as pessoas possam acompanhar a página do Fórum de Saúde do Rio de Janeiro da Frente Nacional Contra a Privatização da Saúde. Diz Marcella: “[...] necessidade constante de [...] defesa desse agir ético e técnico da profissão. A resistência, esse é o momento mais importante para essa palavra! [...]". 


\section{CONCLUSÃO}

Os depoimentos das entrevistadas da live e a pesquisa realizada possibilitam observar que o desmonte das políticas públicas e a retração dos direitos trabalhistas, os "ajustes fiscais permanentes", medidas anteriores ao período pandêmico, são apontados como os principais responsáveis pela barbárie instalada. Assim como evidenciam que o vírus, apesar de sua alta mortalidade e rapidez de disseminação, não causou o colapso no sistema de saúde, a incapacidade de respostas da assistência social e o desemprego alarmante, essa crise já vinha sendo constitucionalizada e executada anteriormente. A demolição de direitos, duramente conquistados, inabilita a Assistência Social e o SUS de atenderem devidamente à população, recaindo sobre os trabalhadores o ônus da descaracterização dos direitos sociais e trabalhistas.

A EC-95 e a terceirização são as formas de precarização e destituição dos direitos sociais e trabalhistas mais mencionadas nesta pesquisa, sendo sinalizadas como as principais responsáveis pela falta de recursos financeiros e humanos da Seguridade Social. De acordo com a pesquisa, isso impulsionou o colapso do SUS, a ineficiência do SUAS e o desemprego latente, aumentando e aprofundando as demandas sociais ao longo do combate à Covid-19. No momento em que a população mais necessita do atendimento do SUS e do SUAS, eles estão em processo de desmantelamento, não podendo responder as necessidades da sociedade. Por sua vez, a terceirização tem deixado os homens e as mulheres descartáveis em situação de total insegurança, milhares de desempregados em busca do auxílio do governo, o que, para muitos, nunca passou do processo de análise.

A associação: desmonte das políticas públicas e retração dos direitos trabalhistas rebate, diretamente, na vida pessoal e no processo de trabalho dos assistentes sociais, observamos isso nos relatos das entrevistadas e por meio da pesquisa realizada, sendo essa situação reproduzida em larga escala. Prova disso são os comentários do vídeo analisado: incapacidade do SUAS e do SUS de atender da população, arranjos institucionais para sanar de forma desorganizada e provisória o que é permanente e anterior a pandemia, várias denúncias de assédio moral, vínculos de trabalhos precários, os transtornos e as ansiedades desenvolvidas nesse período, o medo constante de se contaminar, sem mencionar os inúmeros comentários sobre a falta de EPIs, em várias realidades vivenciadas por profissionais em diferentes regiões do país.

Essa conjuntura requer propostas que possam contribuir para o avanço na Seguridade Social e assegure "a prestação de serviços à população que con- 
tribua para efetivar direitos sociais tão ultrajados na sociedade brasileira". (IAMAMOTO, 2005, p. 164) Os exemplos das duas trabalhadoras da linha de frente, citados neste artigo, mostram que além de atuar no enfretamento a Covid-19, em meio as destituições de direitos sociais e trabalhistas, elas têm que lidar com os desmandos impositivos dos empregadores e com o "surgimento de um conjunto de demandas que vêm para o profissional, quando na verdade, são demandas institucionais!". (MOTA, 2020, informação verbal) Exigindo, assim, dos assistentes sociais extrema atenção e continua aproximação com os conhecimentos teóricos, com a finalidade de desenvolver as competências profissionais e o fortalecimento de iniciativas direcionadas à resistência ao que está posto. Isso se torna ainda mais imprescindível, neste momento, para os que atuam na linha de frente.

Caso contrário, podem acabar sendo envolvidos pela velocidade dos acontecimentos incorrerem em práticas que negam o direito dos usuários e permitindo, sem questionamentos, que "o emergencial se cronifique". (MOTA, 2020, informação verbal) Os relatos das entrevistadas evidenciaram caminhos possíveis, mesmo diante desse cenário, e um posicionamento atitudinal vinculado aos marcos regulatórios da profissão e à classe trabalhadora.

Os assistentes sociais, assim como milhares de outros profissionais da linha de frente, têm perdido suas vidas. Perdido suas vidas para a doença e para um sistema precário que produz milhares de desempregados e que continua reduzindo as condições básicas para tratar e conter o vírus, até então, sem cura. Fica aqui o registro de uma atuação de luta balizada em um projeto societário que prioriza a vida, profissionais que prezam pela ação conjunta e que desenvolvem estratégias coletivamente para uma luta diária por condições de trabalho e de manutenção e ampliação dos direitos sociais e trabalhistas para a população.

\section{REFERÊNCIAS}

ANTUNES, R.; DRUCK, G. A terceirização sem limites: a precarização do trabalho como regra. O Social em Questão, Rio de Janeiro, v. 18, n. 34, p. 19-40, 2015.

ANTUNES, R. L. C. Os sentidos do trabalho: ensaio sobre a afirmação e a negação do trabalho. 2. ed. São Paulo: Boitempo, 2009.

BRASIL. Lei no 8.742, de 7 de dezembro de 1993. Lei Orgânica da Assistência Social. Diário Oficial da União, Brasília, DF, 8 jun. 1993. Disponível em: http:// www.planalto.gov.br/ccivil_03/leis/l8742.htm. Acesso em: 5 set. 2020. 
BRASIL. Constituição (1988). Constituição da República Federativa do Brasil de 1988. Brasília, DF: Presidência da República, [2016]. Disponível em: http://www.planalto.gov.br/ccivil_03/ constituicao/constituicao.htm. Acesso em: 25 jun. 2020.

BRASILEIROS aplaudem profissionais de Saúde pelo combate ao coronavírus. Conselho Federal de Enfermagem, São Paulo, 21 mar. 2020. Covid-19. Disponível em: http://www.cofen.gov.br/brasileiros-aplaudem-profissionais-de-saude-pelo-combateao-coronavirus_78107.html. Acesso em: 22 jun. 2020.

CRISE na Saúde do Rio: entenda o que levou à greve e à restrição no atendimento. G1, Rio de Janeiro, 11 dez. 2019. Rio de Janeiro. Disponível em: https://g1.globo.com/rj/riode-janeiro/noticia/2019/12/11/crise-na-saude-do-rio-entenda-o-que-levou-a-greve-ea-restricao-no-atendimento.ghtml. Acesso em: 20 jul. 2020.

CONSELHO FEDERAL DE SERVIÇO SOCIAL. Parâmetros para a atuação de assistentes sociais na saúde. Versão preliminar. Brasília: CFESS, 2009. Disponível em: http://www.cfess.org.br/arquivos/Parametros_para_Assistentes_Sociais_ na_Saude_-_versao_preliminar.pdf. Acesso em: 29 maio 2020.

CONSELHO FEDERAL DE SERVIÇO SOCIAL. Orientação Normativa $n^{\circ} 3 / 2020$, de 31 de março de 2020. Dispõe sobre ações de comunicação de boletins de saúde e óbitos por assistentes sociais. Brasília: CFESS, 2020. Disponível em: http:// www.cfess.org.br/arquivos/OrientacaoNormat32020.pdf. Acesso em: 27 maio 2020.

CONSELHO REGIONAL DE SERVIÇO SOCIAL SÃO PAULO. Relato da atuação do CRESS/SP em São José do Rio Preto. [São Paulo: CRESS/SP], 2020. Disponível em: http://cress-sp.org.br/wp-content/uploads/2020/04/Texto-COFI_Sjrp_ abr2o_covid.pdf. Acesso em: 1 jun. 2020.

CUNHA, B. Sistema de Saúde do Rio beira ao colapso com 93\% de UTIs ocupadas. Jusbrasil, Rio de Janeiro, 18 abr. 2020. Notícias. Disponível em: https://dp-ri.jusbrasil. com.br/noticias/832924054/sistema-de-saude-do-rio-beira-ao-colapso-com-93-deutis-ocupadas. Acesso em: 23 jun. 2020.

DRUCK, G. Trabalho, precarização e resistências: novos e velhos desafios. Caderno CRH, Salvador, v. 24, n. 1, p. 37-57, 2011. Disponível em: http://www. uff.br/angelo_esther/files/2012/10/RH-I-PRECARIZA\%C3\%87\%C3\%80O-DOTRABALHO-2011.pdf. Acesso em: 19 maio 2020.

EXPRESSÕES sociais: política, direitos e intervenção do serviço social. Plantão da Quarentena \#47. [S. I.: s. n.], 2020. 1 vídeo (2h19min). Publicado pelo canal Esquerda Online. Disponível em: https://www.youtube.com/ watch?v=kgmpXPqUJBk\&t=1758s. Acesso em: 15 maio 2020.

EXPRESSÕES sociais: política, direitos e intervenção do serviço social. Plantão da Quarentena \#47. [S. I.: s. n.], 2020. 1 vídeo (2h19min). Publicado pelo canal Esquerda Online. Disponível em: https://www.youtube.com/watch?v=kg mpXPqUJBk\&list=PLJCjTsoxOhd9g4Z1cexjJpFgQH94TEuwN\&index=2\&t=175 7s. Acesso em: 20 maio 2020. 
FÓRUM MUNICIPAL DE TRABALHADORES/AS DO SISTEMA ÚNICO DE

SAÚDE. Carta abertas do Fórum Municipal dos/as trabalhadores/as do SUAS de SJRP frente à pandemia do coronavírus (Covid-19). São José do Rio Preto: FTMSUAS, 2020. Disponível em: http://cress-sp.org.br/wp-content/uploads/2019/10/CartaAberta-FMTSUAS-SJRP.pdf. Acesso em: 29 maio 2020.

GALVANI, G. Desemprego aumentou antes da chegada do coronavírus no Brasil, mostra IBGE. Carta Capital, São Paulo, 31 mar. 2020. Sociedade. Disponível em: https:// www.cartacapital.com.br/sociedade/desemprego-aumentou-antes-da-chegada-docoronavirus-no-brasil-mostra-ibge/. Acesso em: 3 set. 2020.

GARGALOS deixam mais de 30 milhões sem auxílio emergencial. Jornal da USP, São Paulo, 12 maio 2020. Atualidades. Disponível em: https://jornal.usp.br/ciencias/ gargalos-deixam-mais-de-30-milhoes-sem-auxilio-emergencial/. Acesso em: 1 set. 2020.

GRANEMANN, S. O desmonte das políticas de seguridade social e os impactos sobre a classe trabalhadora: as estratégias e a resistência. Serviço social em Revista, Londrina, v. 19, n. 1, p. 171-184, 2016. Disponível em: http://www.uel.br/revistas/uel/index.php/ ssrevista/article/view/28165. Acesso em: 19 maio 2020.

IAMAMOTO, M. V. O serviço social na contemporaneidade: trabalho e formação profissional. 8. ed. São Paulo: Cortez, 2005.

IAMAMOTO, M. V.; CARVALHO, R. Relações sociais e Serviço Social no Brasil: esboço de uma interpretação histórico-metodológica. 32. ed. São Paulo: Cortez, 2010.

LIMA, M. G. Cress Alagoas lança nota pública em resposta à matéria veiculada em telejornal de Alagoas sobre óbitos de vítimas do Covid-19. Conselho Regional de Serviço Social, Alagoas, 13 maio 2020. Notícias. Disponivel em: http://www.cress16.org.br/noticias/ cress-alagoas-lanca-nota-publica-em-resposta-a-materia-veiculada-em-telejornalde-alagoas-sobre-obitos-de-vitimas-do-covid-19. Acesso em: 22 jun. 2020.

ORGANIZAÇÃO MUNDIAL DA SAÚDE. Boletim do dia 8 de set. de 2020. Suíça: OMS, 2020. Disponível em: https://covid19.who.int/region/amro/country/br. Acesso em: 8 set. 2020.

PINHEIRO, P. S. O novo coronavírus e os trabalhadores invisíveis. Comissão Arns, São Paulo, 2 abr. 2020. Disponível em: https://nev.prp.usp.br/noticias/o-novo-coronaviruse-os-trabalhadores-invisiveis/. Acesso em: 21 jun. 2020.

POR que a doença causada pelo novo vírus recebeu o nome de Covid-19? Fundação Oswaldo Cruz, Rio de Janeiro, 17 mar. 2020. Disponível em: https://portal.fiocruz.br/ pergunta/por-que-doenca-causada-pelo-novo-virus-recebeu-o-nome-de-covid-19. Acesso em: 21 maio 2020.

PREFEITO Crivella segue com o desmonte da Atenção Básica no Rio de Janeiro. Centro Brasileiro de Estudos de Saúde, Rio de Janeiro, 12 mar. 2020. Disponível em: http://cebes. org.br/2020/03/prefeito-crivella-segue-com-o-desmonte-da-atencao-basica-no-riode-janeiro/. Acesso em: 22 jun. 2020. 
PREFEITURA DE RIO PRETO, [2020]. Encontre o que você procura no portal. Disponível em: https://www.riopreto.sp.gov.br/DiarioOficial/Diario.action. Acesso em: 23 jun. 2020.

PROMULGADA Emenda Constitucional do Teto de Gastos Públicos. Senado Notícias, São Paulo, 23 abr. 2018. Congresso. Disponível em: https://www12.senado.leg.br/ noticias/materias/2016/12/15/promulgada-emenda-constitucional-do-teto-de-gastos. Acesso em: 27 jun. 2020.

ROZA, G. Desmonte de Clínicas da Família deixa favelas vulneráveis à Covid-19 no Rio. TAB UOL, São Paulo, 31 mar. 2020. Disponível em: https://tab.uol.com.br/noticias/ redacao/2020/03/31/desmonte-de-clinicas-da-familia-deixa-favelas-vulneraveis-acovid-19-no-rio.htm. Acesso em: 1 jul. 2020.

SATE, R. Demitidos da Viva Rio foram enganados por Crivella. Sindicato dos Auxiliares e Técnicos de Enfermagem do Município do Rio de Janeiro, Rio de Janeiro, 18 fev. 2020. Disponível em: https://satemrj.com.br/2020/02/demitidos-da-viva-rio-foramenganados-por-crivella/. Acesso em: 17 maio 2020.

SÃO JOSÉ DO RIO PRETO. Decreto $n^{\circ} 18.554$, de 16 de março de 2020. Dispõe sobre medidas de prevenção enfrentamento do coronavírus. São José do Rio Preto: Câmara Municipal, [2020]. Disponível em: https://leismunicipais.com.br/a/sp/s/sao-jose-dorio-preto/decreto/2020/1855/18554/decreto-n-18554-2020-dispoe-sobre-medidas-deprevencao-enfrentamento-do-coronavirus. Acesso em: 6 jul. 2020.

SÃO JOSÉ DO RIO PRETO. Portaria $n^{\circ}$ 03/2020, de 23 de março de 2020. Dispõe sobre novas determinações de organização dos atendimentos e serviços da Secretaria Municipal de Assistência Social frente as medidas de prevenção e enfrentamento a pandemia do coronavírus (Covid-19). São José do Rio Preto: Secretaria Municipal de Assistência Social, [2020]. Disponível em: https://www.riopreto.sp.gov.br/wp-content/uploads/arquivosPortalGOV/ coronavirus/PORTARIA-03-2020-SEMAS.pdf. Acesso em: 22 jun. 2020.

SECRETARIA DE SAÚDE DO RIO DE JANEIRO. Resolução SMS nº 4369, de 15 de abril de 2020 . Orientação sobre suspenção das visitas aos pacientes internados na rede da SMS do Município do Rio de Janeiro frente a pandemia do Covid-19. Diário Oficial do Município do Rio de Janeiro: Rio de Janeiro, 2020. Disponível em: https://pge.rj.gov.br/comum/code/MostrarArquivo. php?C=MTA2MzU\%2C. Acesso em: 29 maio 2020.

\section{SECRETARIA MUNICIPAL DE ASSISTÊNCIA SOCIAL DE SÃO JOSÉ DO} RIO PRETO. Portaria SEMAS n ${ }^{\circ} 03 / 2020$, de 23 de março de 2020. Dispõe sobre novas determinações de organização dos atendimentos e serviços da Secretaria Municipal de Assistência Social frente as medidas de prevenção e enfrentamento a pandemia do coronavírus (Covid-19). Diário Oficial do Município de São José do Rio Preto: São José do Rio Preto, 2020. Disponível em: https:// www.riopreto.sp.gov.br/wpcontent/uploads/arquivosPortalGOV/coronavirus/ PORTARIA-03-2020-SEMAS.pdf. Acesso em: 28 maio 2020. 
SECRETARIA MUNICIPAL DE ASSISTÊNCIA SOCIAL de SÃO JOSÉ DO RIO PRETO. Portaria SEMAS n ${ }^{\circ}$ 06/2020, de 09 de abril de 2020. Dispõe sobre NOVAS determinações de organização dos atendimentos e serviços da Secretaria Municipal de Assistência Social frente as atualizações das demandas e ações em medidas de prevenção e enfrentamento a pandemia do coronavírus (Covid-19). Diário Oficial do Município de São José do Rio Preto: São José do Rio Preto, 2020. Disponível em: https://www.riopreto.sp.gov.br/ DiarioOficial/Diario.action. Acesso em: 29 maio 2020.

TANIGUCHI, N. Covid-19: ponto a ponto sobre o novo coronavírus. FioCruz Brasília, Brasília, 20 mar. 2020. Disponível em: https://www.fiocruzbrasilia.fiocruz.br/covid19-ponto-a-ponto-do-novo-coronavirus/. Acesso em: 19 jun. 2020.

TAVARES, V. Os dados invisíveis da Covid-19. Escola Politécnica de Saúde Joaquim Venâncio, Rio de Janeiro, 14 maio 2020. Reportagem. Disponível em: http://www.epsjv.fiocruz. $\mathrm{br} /$ noticias/reportagem(os)--dados-invisiveis-da-covid-19. Acesso em: 20 jun. 2020.

TELLES, V. S. Direitos sociais: afinal, do que se trata? Revista USP, São Paulo, n. 37, p. 34-45, 1998.

TCHAO, E. Prefeitura do Rio começa a demitir funcionários do programa Clínica da Família. G1, Rio de Janeiro, 17 jan. 2019. Disponível em: https://g1.globo.com/rj/riode-janeiro/noticia/2019/01/17/prefeitura-do-rio-comeca-a-demitir-funcionarios-doprograma-clinica-da-familia.ghtml. Acesso em: 20 jun. 2020.

THUSWOHL, M. Afastados e terceirizados, técnicos de enfermagem sofrem com perda salarial no Rio de Janeiro. Rede Brasil Atual, São Paulo, 1 maio 2020. Trabalho. Disponível em: https://www.redebrasilatual.com.br/trabalho/2020/05/enfermeirossaude-corte-salario/. Acesso em: 1 jul. 2020.

TRABALHADORAS(es) do SUAS de São José do Rio Preto atuam com dificuldades durante a pandemia da Covid-19. Conselho Regional de Serviço Social de São Paulo, São Paulo, 14 abr. 2020. Notícias. Disponível em: http://cress-sp.org.br/trabalhadorasesdo-suas-de-sao-jose-do-rio-preto-atuam-com-dificuldades-durante-a-pandemia-dacovid-19/. Acesso em: 26 jun. 2020. 